\title{
DESAIN EKSPERIMEN PENGARUH PENAMBAHAN WATER PROOFING TERHADAP NILAI KUAT TEKAN BETON
}

\author{
Asep Rahmatullah ${ }^{1)}$, Dedy Khaerudin ${ }^{2)}$ \\ ${ }^{12}$ Fakultas Teknik, Universitas Bina Bangsa \\ email: asep.rahmatullah@binabangsa.ac.id
}

\begin{abstract}
Abstrak: Pembangunan perkerasan jalan raya dengan menggunakan beton (betonisasi) memberikan manfaat dari segi lamanya umur suatu jalan apabila dibandingkan dengan menggunakan pekerasan Aspalt Hotmix (Laston AC-WC). Permasalahan yang terjadi dalam pelaksanaan pekerjaan proyek konstruksi jalan beton adalah terjadinya beton setting. Ketika terjadi hal tersebut biasanya pihak ketiga menambahkan air kedalam mixer beton untuk mengatasi hal tersebut, agar beton tersebut bisa dihamparkan. Sehingga tujuan dalam penelitian ini yaitu mencari pengaruh penambahan water proofing terhadap kuat tekan beton. Data hasil pengamatan diolah dengan menggunakan metode One Way Anova serta Metode Tukey untuk mengetahui tingkat signifikansi dari data pengamatan tersebut. Hasil uji diperoleh bahwa untuk uji One Way Anova nilai $F_{\text {hitung }}=144,30$ sedangkan untuk nilai $F_{\text {tabel }}$ adalah $F_{0,95}(3,44)=2,82$, sedangkan dari uji tukey dihasilkan P-Value pada seluruh pasangan bernilai 0,000, yg berarti nilai $P$-Value $\leq \alpha(0,05)$. Oleh sebab itu penambahan komposisi water proofing memberikan pengaruh yang signifikan terhadap kuat tekan beton.
\end{abstract}

Kata kunci: Beton Setting, One Way Anova, Metode Tukey, Water Proofing

\begin{abstract}
Construction of road pavement using concrete (Concrete Pavement) provides benefits in terms of the age of a road when compared to using Asphalt Hotmix (Laston AC-WC) pavement. The problem that occurs in the implementation of concrete road construction project work is the occurrence of concrete settings. When this happens the third party usually adds water to the concrete mixer to overcome this, so that the concrete can be spread out. So the purpose of this research is to look for the effect of adding waterproofing to the compression strength of concrete. Observation data were processed using the One Way ANOVA method and the Tukey Method to determine the significance level of the observational data. The test results obtained that for the One Way Anova test the value of count $=144.30$ while for the value of the table is F0.95 (3.44) $=2.82$, while the Tukey test produced $P$-Value for all pairs is 0,000, which means the value P-Value $\leq \alpha(0.05)$. Therefore, the addition of the composition of waterproofing has a significant effect on the compression strength of concrete.
\end{abstract}

Keywords: concrete setting, OneWay Anova, Tukey Method, Waterproofing

\section{PENDAHULUAN}

Kualitas pembangunan struktur perkerasan jalan raya menjadi isu yang sangat penting, karena sub sektor infrastruktur ini memberikan pengaruh besar pada sektor pembangunan ekonomi dan sektor perkembangan sosial masyarakat. Dalam perkembangan pembangunan konstruksi jalan, struktur perkerasan jalan diarahkan dengan menggunakan betonisasi (Rigid Pavement). Hal ini disebabkan karena perkerasan jalan dengan betonisasi memberikan manfaat dari segi lamanya umur jalan dibandingkan dengan perkerasan jalan dengan menggunakan Aspalt Hotmix (Laston AC-WC).

Pengembangan dan penelitian terhadap struktur beton serta bahan aditifnya terus dikembangkan oleh pihak pemerintah melalui Kementerian Pekerjaan Umum dan Penaataan Ruang (Kementerian PUPR) ataupun oleh pihak akademisi, guna mendapatkan kualitas mutu beton yang lebih tinggi.

Akan tetapi banyak permasalahan yang terjadi khususnya didalam pelaksanaan pekerjaan proyek konstruksi betonisasi jalan raya, selain dari faktor pemerintah dalam aspek lamanya waktu proses penganggaran yang menyebabkan waktu pekerjaan lapangan yang menjadi relatif singkat serta faktor pihak ketiga yang terkesan mengabaikan aspek perawatan pasca penghamparan beton dilakukan, hal ini terjadi dikarenakan pihak ketiga mengejar target penyelesaian pekerjaan yang dirasa relatif singkat. 
Selain daripada itu, permasalahan yang terjadi dilapangan ketika proses pelaksanaan proyek berlangsung sering terjadinya Beton Setting. Beton Setting terjadi akibat penurunan kadar air dalam campuran beton yang cukup tinggi sehingga mempengaruhi pada slump beton sebagai alat untuk melihat mutu campuran beton yang diproduksi.

Apabila permasalahan beton setting terjadi, biasanya pihak ketiga langsung menambahkan air kedalam mixer beton, sebagai upaya mengatasi beton setting tersebut. Permasalahan selanjuntnya ketika pemberian air terlalu banyak, akan menyebabkan beton menjadi encer dan titik slump pun menjadi kecil. Pertanyaan yang kemudian muncul adalah berapa kuat tekan beton yang dihasilkan?apakah sesuai dengan mutu yang dipesan atau sebalik nya. Hal ini lah yang menjadi konsen penulis dalam melakukan penelitian ini.

Tujuan penelitian ini adalah mencari pengaruh dari penambahan water proofing dalam campuran beton terhadap kuat tekan beton itu sendiri.

\section{METODE PENELITIAN \\ Sumber Data}

Data yang digunakan dalam penelitian ini merupakan data sekunder yang diambil dari laporan hasil percobaan uji tekan beton mutu K-175 di laboratorium Dinas Bina Marga dan Tata Ruang Kabupaten Serang.

\section{Flow Chart Penelitian}

Tahapan yang dilakukan dalam penelitian ini dapat dilihat pada gambar 1.

\section{Analisa Varians satu Arah (One-Way ANOVA)}

One-Way Anova merupakan analisa varian yang dihasilkan dari pengaruh satu faktor. Dari tiap populasi independen diambil sebuah sampel acak yang dinyatakan dengan $\mathrm{Y}_{\mathrm{ij}}$ yang berarti data ke-j dalam sample yang diambil dari populasi ke-i. Seperti terlihat tabel 1.

Setelah penyusunan dan nilai total serta nilai rata-rata diperoleh, maka disusunlah sebuah Tabel Anova seperti pada tabel 2. dalam tabel tersebut terdapat 3 sumber variasi yaitu variasi antar treatments, variasi dalam treatments serta total. Masing-masing sumber variasi memiliki derajat kebebasan (d.f.) yang besarnya (a-1) untuk variasi antar treatments, $(\mathrm{N}-\mathrm{a})$ untuk variasi dalam treatments, dan $(\mathrm{N}-$ 1) untuk total.
Dari data hasil pengamatan dan perhitungan dalam tabel Anova yang diperoleh, kemudian akan ditarik kesimpulan dengan cara menentukan kriteria pengujian hipotesa : Jika $\mathrm{F}_{\text {hitung }} \geq \mathrm{F}_{\text {tabel, }}$ maka $\mathrm{H}_{0}$ berarti ditolak dan $\mathrm{H}_{1}$ diterima, yang artinya faktor memberikan pengaruh, begitupun sebaliknya. Untuk pengambilan keputusan dengan taraf signifikansi 0,05 atau 0,01 maka kriterianya : Jika nilai $p \geq \alpha$, maka $\mathrm{H}_{0}$ diterima, apabila $p \leq$ $\alpha$, maka $\mathrm{H}_{0}$ ditolak

Tabel 1. Tipikal data untuk Single Faktor Experiment

\begin{tabular}{|c|c|c|c|c|c|c|}
\hline $\begin{array}{l}\text { Treatment } \\
\text { (Level) }\end{array}$ & & Observations & & & Totals & Averages \\
\hline 1 & $y_{\| 1}$ & $y_{12}$ & $\ldots$ & $y_{\mid n}$ & $y_{\mathrm{L}}$ & $\bar{y}_{1 .}$ \\
\hline 2 & Via & $y_{22}$ & $\ldots$ & $y=n$ & 12. & $\bar{y}_{2}$ \\
\hline$\vdots$ & $\vdots$ & $\vdots$ & $\ldots$ & $\vdots$ & $\vdots$ & $\vdots$ \\
\hline$a$ & $y_{a l}$ & $y_{02}$ & $\cdots$ & $y_{a n}$ & $\frac{y_{\text {e. }}}{y_{.}}$ & $\frac{\bar{y}_{u}}{\bar{y}_{u}}$ \\
\hline
\end{tabular}

Tabel 2. Tipikal data untuk Single Faktor Experiment

\begin{tabular}{|c|c|c|c|c|}
\hline Source of Variation & $\begin{array}{l}\text { Sum of } \\
\text { Squares }\end{array}$ & $\begin{array}{l}\text { Degrees of } \\
\text { Freedom }\end{array}$ & $\begin{array}{l}\text { Mean } \\
\text { Square }\end{array}$ & $F_{0}$ \\
\hline Between treatments & $\begin{array}{l}S S_{\text {Trealmets }} \\
\quad=n \sum_{i=1}^{d}\left(\bar{y}_{i}-\bar{y}_{.}\right)^{2}\end{array}$ & $a-1$ & $M S_{\text {Treuments }}$ & $F_{0}=\frac{M S_{\text {Treatments }}}{M S_{E}}$ \\
\hline Error (within treatments) & $s s_{E}=s s_{T}-s s_{\text {Treatmeats }}$ & $N-a$ & $M S_{E}$ & \\
\hline Total & $S S_{\mathrm{T}}=\sum_{i=1}^{b} \sum_{=1}^{\pi}\left(y_{i j}-\bar{y}_{. .}\right)^{2}$ & $N-1$ & & \\
\hline
\end{tabular}

\section{Metode Tukey}

Tukey semula mengusulkan suatu metode yang mana diketahui sebagai metode HSD (Honestly Significant Difference Method) dan metode ini dikenal dengan uji Beda Nyata Jujur (BNJ). Analisa ini digunakan ketika data dalam penelitian dilakukan dengan cara membandingkan dat dua kelompok sampel yang jumlahnya sama. Pengujian hipotesis metode Tukey adalah sebagaimana berikut : Hipotesis :

$$
\begin{aligned}
& \mathrm{H}_{0}: \mu_{\mathrm{A}}=\mu_{\mathrm{B}} \quad \mu_{\mathrm{A}}=\text { Rerata data kelompok } \\
& \text { eksperimen } \\
& \mathrm{H}_{1}: \mu_{\mathrm{A}}>\mu_{\mathrm{B}} \quad \mu_{\mathrm{B}}=\text { rerata data kelompok } \\
& \text { Control }
\end{aligned}
$$

Pendekatan rumus yang diambila pada uji ini adalah sebagai berikut :

Tukey Test $=\frac{\overline{\mathrm{Y}}_{\mathrm{A}}-\overline{\mathrm{Y}}_{\mathrm{B}}}{\sqrt{\frac{\mathrm{RKK}(\mathrm{D})}{\mathrm{N}}}}=\frac{\overline{\mathrm{Y}}_{\mathrm{A}}-\overline{\mathrm{Y}}_{\mathrm{B}}}{\sqrt{\frac{\mathrm{S}^{2}}{\mathrm{n}}}}$ 
$S^{2}=R J K(D)=\frac{J K(D)}{d k(D)}=\frac{\sum Y_{T}^{2}-\sum \frac{\left(\sum Y_{\mathrm{i}}\right)^{2}}{n_{i}}}{n_{T}}=\frac{\sum Y_{T}^{2}-\left(\sum \frac{\left(\sum Y_{A}\right)^{2}}{n_{A}}+\frac{\left(\sum Y_{B}\right)^{2}}{n_{B}}\right)}{n_{T}-k, b}$

Dimana ;

$\mathrm{Y}_{\mathrm{A}} \quad=$ Rata-rata skor kelompok eksperimen

$\mathrm{Y}_{\mathrm{B}} \quad=$ Rata-rata skor kelompok kontrol

$\mathrm{S}^{2} \quad=$ Varian gabungan

$n \quad=$ Banyaknya sampel dalam satu pasangan (eksperimen + kontrol)

$n=n_{A}=n_{B}$

$n_{T} \quad=$ Banyaknya sampel total

$n_{T}=n_{A}+n_{B}$

$k=$ Banyaknya kolom $=2$

$b \quad=$ Banyaknya baris $=1$

Untuk pengujian hipotesis, selanjutnya nilai $Q_{h}$ (Q hitung dibandingkan dengan nilai dari tabel distribusi tukey (Q tabel). Penentuan nilai Q tabel didasarkan pada taraf signifikansi yang ditentukan oleh peneliti bisa dengan 0,05 (95\%) atau 0,01 (99\%).

\section{Hipotesa Penelitian}

Penulis membuat hipotesis pada penelitian ini adalah sebagaimana berikut:

$\mathrm{H}_{0}: \mu 1=\mu 2$

$\mathrm{H}_{1}$ : tidak semua rata-rata populasi sama Jadi,

$\mathrm{H}_{0} \quad$ : Tidak ada pengaruh Penambahan Komposisi Water Proofing (\%)

terhadap Kuat Tekan Beton

$\mathrm{H}_{1} \quad$ :Terdapat Pengaruh Penambahan Komposisi Water Proofing (\%)

Terhadapa Kuat Tekan Beton

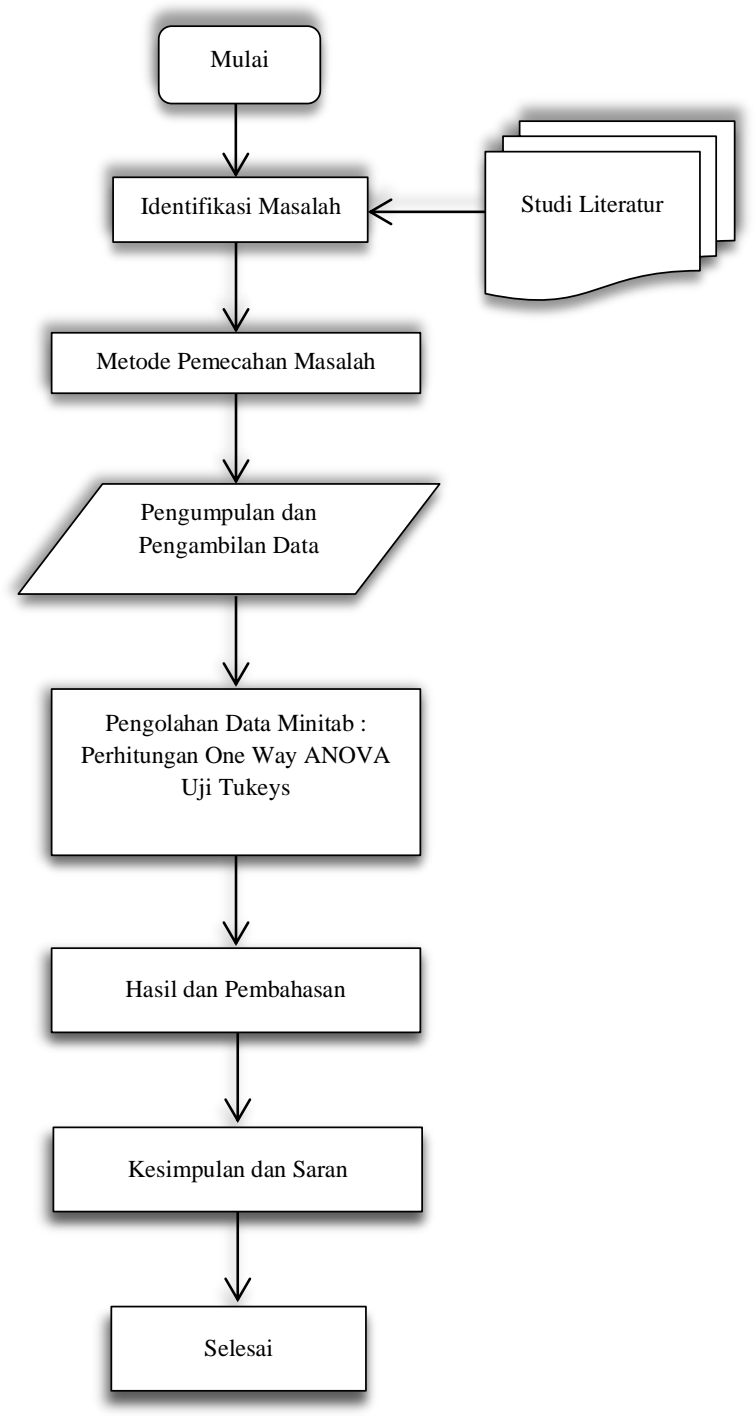

Gambar 1. Alur Penelitian

\section{HASIL DAN PEMBAHASAN}

Hasil Uji Kuat Beton

Dari percobaan penambahan komposisi water proofing, diperoleh hasil uji tekan beton sebagaimana berikut :

Tabel 3. Hasil Uji Kuat Tekan Beton

\begin{tabular}{ccccc}
\hline Benda & \multicolumn{4}{c}{ Komposis Water Proofing } \\
\cline { 2 - 5 } Uji & 0,5 & 1 & 1,5 & 2 \\
\hline $\mathbf{1}$ & 93 & 131 & 166 & 191 \\
$\mathbf{2}$ & 91 & 120 & 167 & 184 \\
$\mathbf{3}$ & 89 & 119 & 166 & 191 \\
$\mathbf{4}$ & 87 & 132 & 144 & 180 \\
$\mathbf{5}$ & 83 & 133 & 155 & 191 \\
$\mathbf{6}$ & 80 & 122 & 150 & 187 \\
$\mathbf{7}$ & 82 & 80 & 150 & 171 \\
\hline
\end{tabular}




\begin{tabular}{ccccc}
\hline $\mathbf{8}$ & 80 & 89 & 148 & 191 \\
$\mathbf{9}$ & 76 & 72 & 140 & 169 \\
$\mathbf{1 0}$ & 80 & 118 & 159 & 195 \\
$\mathbf{1 1}$ & 89 & 123 & 156 & 181 \\
$\mathbf{1 2}$ & 72 & 121 & 157 & 167 \\
\hline
\end{tabular}

\section{Uji One Way Anova}

Dari hasil data uji tekan beton pada tabel 1 diatas, maka kita dapat melakukan uji one way anova terhadap data tersebut. Dengan mengasumsikan bahwa waktu perendaman beton tidak termasuk pada variabel yang diuji, karena waktu perendaman beton merupakan syarat mutlak terhadap uji tekan beton, sesuai dengan pedoman pengujian tekan beton (SNI 03 - 1974 - 1990).

Data diatas kemudian kita lakukan pengkodingan (kurangi dengan 100) guna mempermudah pengolahan data, sehingga data yang diperoleh sebagaimana terlihat pada Tabel 2.

Tabel. 5. Coding Data Hasil Uji Tekan

\begin{tabular}{ccccc}
\hline Benda & \multicolumn{4}{c}{ Water Proofing } \\
\cline { 2 - 5 } Uji & $\mathbf{0 , 5}$ & $\mathbf{1}$ & $\mathbf{1 , 5}$ & $\mathbf{2}$ \\
\hline 1 & -7 & 31 & 66 & 91 \\
2 & -9 & 20 & 67 & 84 \\
3 & -11 & 19 & 66 & 91 \\
4 & -13 & 32 & 44 & 80 \\
5 & -17 & 33 & 55 & 91 \\
6 & -20 & 22 & 50 & 87 \\
7 & -18 & -20 & 50 & 71 \\
8 & -20 & -11 & 48 & 91 \\
9 & -24 & -28 & 40 & 69 \\
10 & -20 & 18 & 59 & 95 \\
11 & -11 & 23 & 56 & 81 \\
12 & -28 & 21 & 57 & 67 \\
\hline
\end{tabular}

Data hasil coding tersebut kemudian dilakukan pengolahan data uji one way anova menggunakan software minitab versi 17 dengan tingkat kepercayaan $\alpha=95 \%$.

Dari hasil olah data diperoleh untuk nilai $\mathrm{F}_{\text {hitung }}$ $=144,30$ sedangkan untuk nilai $F_{\text {tabel }}$ adalah $\mathrm{F}_{0,95(3,44)}=2,82$. Hal ini menunjukan bahwa $\mathrm{F}_{\text {hitung }} \geq \mathrm{F}_{\text {tabel }}$ yang berarti bahwa $\mathrm{H}_{0}$ ditolak pada taraf 0,05 dan hasil pengujian bersifat signifikan. Artinya keputusan penambahan komposisi water proofing pada campuran beton akan mempengaruhi kepada uji kuat tekan beton. Sedangkan P-Value dari hasil pengolahan data bernilai $\mathrm{P}$-Value $=0,000$, karena $\mathrm{P}$-Value $\leq \alpha$, maka $\mathrm{H}_{0}$ pun ditolak yang.

Hasil pengolahan data dengan minitab 17 dapat dilihat sebagaimana berikut :

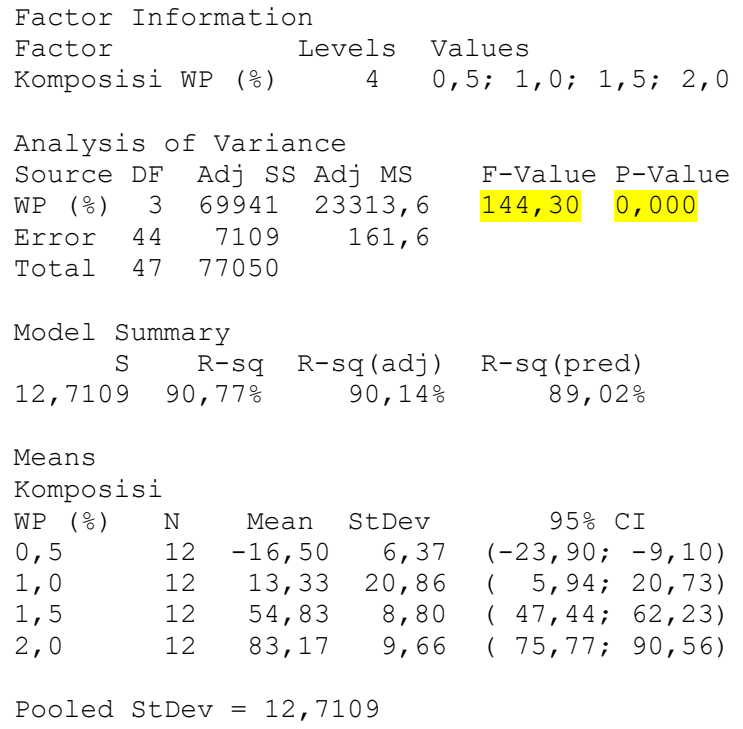

Sedangkan dari hasil tampilan gambar 1 Residual Polts terlihat bahwa :

1. Normal Probability Plot memperlihatkan penyebaran residual plots dan rata rata mendekati titik 0 .

2. Histogram Residual Plots memperlihatkan bahwa rata-rata residual berdistribusi normal.

3. Residual Versus The Fits Value memperlihatkan residual tersebar acak.

4. Residual Versus The Order Data memperlihatkan secara random residual bergerak secara fluktuatif yang berarti tidak ada korelasi dianatara error (independent error)

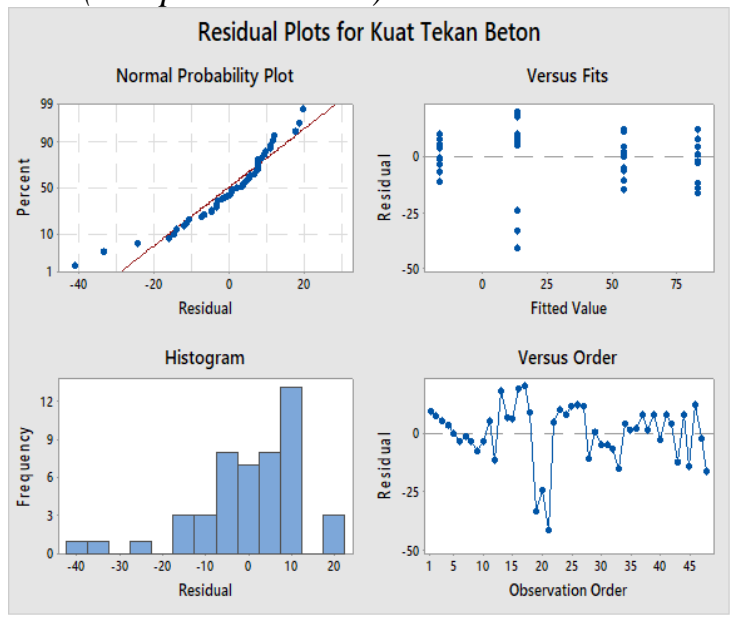

Gambar 2 Residual Plots Data 


\section{Uji Tukeys}

Setelah melakukan pengujian ANOVA, untuk mendapatkan hasil yang lebih signifikan dari penelitian ini, maka perlu dilakukan pengujian lanjutan. Pengujian lanjutan yang digunakan oleh penulis yaitu dengan menggunakan Uji Tukey atau biasa yang disebut dengan uji Beda Nyata Jujur (BNJ).

Dari hasil uji BNJ terlihat bahwa nilai sig $P$ Value dari keempat pasangan perbandingan kurang dari $\alpha=0,05$ ( $P$-Value $\leq \operatorname{sig} \alpha 0,05)$, yang berarti bahwa rata-rata tiap skor faktor berbeda signifikan dengan rata-rata skor faktor yang lain. Hal ini bisa mengandung pengertian bahwa keempat pasangan faktor tersebut sangat mempengaruhi kepada uji kuat tekan beton. Hasil uji BNJ dengan minitab dapat dilihat sebagaiman berikut :

\section{Tukey Pairwise Comparisons}

Grouping Information Using the Tukey Method and $95 \%$ Confidence

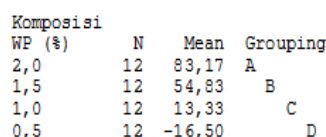

Means that do not share a letter are significantly different.

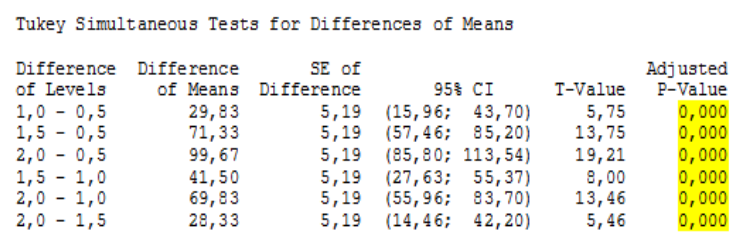

Individual confidence leve $1=98,95 \%$

\section{KESIMPULAN}

Dari hasil analisis data penelitin yang telah dilakukan dengan menggunakan Minitab versi 17 diperoleh kenyataan bahwa nilai $\mathrm{F}_{\text {hitung }}$ $\geq \mathrm{F}_{\text {tabel }}($ One way anova) dan $P$-Value $\leq \operatorname{sig} \alpha$ 0,05 (Tukeys Test) yang menginterpretasikan $\mathrm{H}_{0}$ ditolak. Sehingga penambahan komposisi water proofing (\%) secara signifikan berpengaruh terhadap respon uji kuat tekan beton. Oleh sebab itu, penambahan air pada saat terjadinya beton setting tidak boleh dilakukan, lebih baik beton tersebut dikembalikan ke batching plant dan batching plant harus mengganti beton tersebut sebagai upaya menjaga kualitas beton yang dihasilkan. Penelitian ini masih sangat bersifat sederhana sehingga perlu dilakukan penelitian lanjutan dari beberapa faktor yang lain terhadap uji kuat tekan beton seperti pengaruh perendaman/penyiraman beton, penambahan komposisi aditif dalam campuran beton, pengaruh jarak batching plant terhadap kualitas pekerjaan beton, dan lain-lain.

\section{DAFTAR PUSTAKA}

Abdul Wahdi, K, dkk. Usulan Level Faktor Variasi Bahan untuk Mencapai Kuat Tekan Beton 50 Mpa dengan Metode Perancangan Eksperimen. Jurnal Online Institut Teknologi Nasional No. 2 Vol 01. 2013.

Ahmad Aswani, Irma. Dkk. Analisa Pengaruh Temperatur Terhadap Kuat Tekan Beton. Jurnal Teoritis dan Terapan Bidang Rekayasa Sipil Vol 16 No 2. 2009.

Badan Standardisasi Nasional. Metode Pengujian Kuat Tekan Beton SNI 031974-1990. Jakarta. Badan Standarisasi Nasional.

Badan Standardisasi Nasional. Metode Pengujian Untuk Mengukur Nilai Kuat Tekan Beton pada Umur Awal Beton dan Memproyeksikan Kekuatan pada Umur Berikutnya SNI 03-6805-2002. Jakarta. Badan Standarisasi Nasional.

Fajri Syco, Rezano, dkk. Pengaruh Pemakaian Agregat Kasar dari Limbah AMP Terhadap Kuat Beton $f_{c}$ ' 18,5 Mpa. Jurnal Ilmiah Fakultas Teknik Universitas Pasir Pengaraian.

Gaspersz, V. Teknik Analisis Dalam Penelitian Percobaan I. Bandung. PT. Tarsito. 1991.

Kementerian Pekerjaan Umum. Peraturan Beton Bertolang Indonesia 1971 N.I.2. Cetakan 2 . Direktorat Penyelidikan Masalah Bangunan. Jakarta

Nainggolan, B. Perbandingan Uji Tukeys (Uji Beda Nyata Jujur (BNJ)) dengan Uji Fisher (Uji Beda Nyata Terkecil (BNT)) Dalam Uji Lanjut Data Rancangan Percobaan. 2009. Majalah Ilmiah Panorama Nusantara Edisi VIII. 
Neter ,. J., et al. Applied Linear Statistical Models, Fourth Edition. Boston. McGraw-Hill. 1996.

Nurhayati, Iis K,. Windya Giri RR,. Analisis Perbandingan Nilai TOEFL dengan Nilai Mata Kuliah Bahasa Inggris Mahasiswa. Jurnal Sosioteknologi Vol 13 No 2. 2014.

Megasari, W.M., Winayati. Analisis Pengaruh Penambahan Sikament-NN Terhadap Karakteristik Beton. $2017 . \quad$ Jurnal Teknik Sipil Siklus Vol.3 No 22.

Montgomery, D.C. Design And Analysis of Experiments Eighth Edition. New York. John Wiley \& Sons Inc. 2012.

Mulyono, T., Teknologi Beton. Yogyakarta. Penerbit Andi. 2006.

Sudjana,. Desain dan Analisi Eksperiment. Edisi ke-4. Bandung : PT Tarsito. 2002. 